\title{
Posterior Approach to Internal Jugular Vein Cannulation is Superior to Central Approach in Terms of Ease of Insertion and Less Complication - A One Year Hospital Based Randomised Controlled Trial
}

\author{
Kedareshvara K.S. ${ }^{1}$, Neeraj Chopra ${ }^{2}$, Manjunath Patil ${ }^{3}$ \\ 1,2,3 Department of Anaesthesiology, Jawaharlal Nehru Medical College, \\ KLE Academy of Higher Education and Research, Belgaum, Karnataka, India.
}

\section{ABSTRACT}

\section{BACKGROUND}

Among the different large veins that can be cannulated, the right internal jugular vein (IJV) is the most preferred. Cannulation of the right IJV is most commonly done using the landmark guided central approach but it is associated with a higher risk of carotid puncture. In this context, posterior approach has been found to be better and safer. We wanted to compare the placement of an IJV cannula via central versus posterior approach in terms of attempts and time to locate the vein, duration of cannulation and complications.

\section{METHODS}

A randomised controlled trial of 120 adult patients divided into two groups of 60 each to be cannulated by either the central or the posterior approach was done. Success rate and time taken to locate IJV, time taken for cannulation, number of carotid punctures and other complications were assessed. Collected data was analysed using chi-square test / Fisher exact test.

\section{RESULTS}

Our analysis showed that in the posterior approach group, the vein was located faster $(12.04 \pm 1.49 \mathrm{~s}$ vs. $14.27 \pm 2.30 \mathrm{~s}, \mathrm{p}<0.001)$ and with fewer attempts $51(85 \%)$ vs. $42(70 \%), p=0.054$ and the duration of cannulation was also shorter $(205.54 \pm 29.58$ $\mathrm{s}$ vs. $278.51 \pm 41.14 \mathrm{~s}, \mathrm{p}<0.001)$. Arterial punctures were more with the central approach (13 vs. $3, \mathrm{p}<0.001)$.

\section{CONCLUSIONS}

The posterior approach has a higher first attempt success rate, shorter duration of cannulation and lower incidence of complications. It is a viable and efficient alternative to the central approach but involves a small learning curve.

\section{KEY WORDS}

Central Venous Catheter, Internal Jugular Vein, Posterior Approach, Central Approach
Corresponding Author: Dr. Neeraj Chopra, Department of Anesthesiology, Jawaharlal Nehru Medical College, KLE Academy of Higher Education and Research, Belgaum,

Karnataka, India.

E-mail: chopda.n@gmail.com

DOI: $10.14260 / j e m d s / 2020 / 844$

How to Cite This Article:

Kedareshvara K.S, Chopra N, Patil M. Posterior approach to internal jugular vein cannulation is superior to central approach in terms of ease of insertion and less complication - a one-year hospital based randomised controlled trial. J Evolution Med Dent Sci 2020;9(51):3846-3851, DOI: 10.14260/jemds/2020/844

Submission 11-08-2020,

Peer Review 29-10-2020,

Acceptance 05-11-2020,

Published 21-12-2020.

Copyright (c) 2020 JEMDS. This is an open access article distributed under Creative Commons Attribution License [Attribution 4.0 International (CC BY 4.0)] 


\section{BACKGROUND}

Establishing a central venous access has been experimented from the $19^{\text {th }}$ century and refined over the years and in the last 60 years has become safer for both the patient and the anaesthesiologist.1,2,3 Compared to all major veins like femoral vein, subclavian vein and left internal jugular vein the right internal jugular vein catheterization has many advantages. Embryologically, the internal jugular veins are derivatives of right and left anterior cardinal veins which then along with the common cardinal vein formed the superior vena cava. The internal jugular vein originates as a direct continuation of the sigmoid sinus, which is also joined by the superior and inferior petrosal sinus, it then exists cranium via the jugular foramen. Fast forward to the present and ultrasound guided placement of central venous cannula using the Seldinger technique has now become a standard of care, to improve the success rate and reduce the complications. 4,5

Right internal jugular vein is often preferred for securing central venous catheterization because of many factors like, direct course to superior vena cava and consistent anatomical location, it is easy to compress when bleeding and there will lower incidence of pneumothorax.

Many studies earlier were carried out in order to make easy access into right internal jugular vein catheterization, one such example is keeping shoulder rest and head in extension makes the carotid artery, two heads of the sternocleidomastoid and external jugular veins are made prominent and more visible. This manure had helped more specially in obese and short necked patients.

In addition to shoulder rest Trendelenburg position, the head is kept in neutral position and turned to left side is also studied in order to access right internal jugular vein successfully.

Among the different large veins that can be cannulated the most commonly selected is the right internal jugular vein, for its straight course to the right side of the heart, lack of valves, mostly predictable anatomy and ease of cannulation. ${ }^{6-8}$ While ultrasound guided placement is ideal ${ }^{9}$ not all institutions have the equipment, hence even today a majority of the central venous catheters are placed based on the traditional landmark guided approaches. While each approach has its merits and demerits, the onus falls upon us to find out the best approach to minimize the complications inherent to the landmark-based approaches.9,10 The cannulation is commonly performed using the central or landmark approach, i.e., at apex of triangle formed by the two heads of sternocleidomastoid. This approach is easier for beginners to learn and hence popular but carries a higher risk of carotid puncture, haematoma formation and pneumothorax.11-13

Comparatively, the posterior approach i.e. behind the lateral border of sternocleidomastoid (SCM), is practiced less frequently but in a few studies has been found to be a better approach than the standard central approach with fewer incidences of complications and easier access to the vein. ${ }^{11}$ Thus, this study, a randomized control trial, was undertaken to compare the above two approaches and find out if indeed the posterior approach is better than the central approach in cannulating the internal jugular vein on the right side in terms of success of cannulation and complications.

\section{METHODS}

A one-year hospital based randomised controlled trial was conducted at KLE'S Dr. Prabhakar Kore Hospital and MRC, Belagavi. In total, 120 patients eligible were requiring internal jugular vein cannulation in the operation theatre and critical care unit at a single tertiary care centre, between $1^{\text {st }}$ January 2018 and 31 ${ }^{\text {st }}$ December 2018. Ethical clearance for this study was taken from the Institutional Ethical Board. Written and informed consent was taken from each patient separately in their own vernacular language. The sample size was calculated using the formula

$\frac{N=(Z \alpha+Z \beta) 2 p(1-p)}{D 2}$

$\frac{\mathrm{P}=\mathrm{P} 1+\mathrm{P} 2}{2}$

and

$\mathrm{d}=\mathrm{P}_{1}-\mathrm{P}_{2}$

Where $\mathrm{p} 1$ and $\mathrm{p} 2$ are the proportions (\%) of the two groups $\mathrm{Z} \alpha$ is linked with the level of significance and $\mathrm{Z} \beta$ is linked with the power of the test.

For $5 \%$ level of significance $\mathrm{Z} \alpha=1.96$ and $\mathrm{Z} \beta=0.84$ for 80 $\%$ power of the test. By taking proportion of success in the first attempt $\mathrm{p} 1=52 \%$ and $\mathrm{p} 2=80 \%$ of the sample size obtained is 45 . To improve the validity of study a sample size of 60 in each group has been taken.

\section{Inclusion Criteria}

Patients aged between 18 to 80 years, belonging to (American Society of Anaesthesiologist) physical status I / II / III for either elective / emergency surgery or in the critical care unit requiring central venous access were included in the study.

\section{Exclusion Criteria}

Patients with coagulopathy (INR > 1.5), infection at the site of insertion and prior neck surgery were excluded from the study.

Patients were divided into two groups randomly by using computer generated number table. The eligible patients were randomly divided into two groups of 60 each to undergo right internal jugular vein cannulation. Group $\mathrm{C}$ to undergo cannulation via the central approach Group $\mathrm{P}$ to undergo cannulation via the posterior approach.

All patients initially had standard monitors connected which included non-invasive blood pressure, pulse oximeter and electrocardiogram. Baseline blood pressure, heart rate and peripheral $\mathrm{O}_{2}$ saturation were recorded, patients for surgery were then anaesthetised according to the institutions protocols and then positioned. Based on study conducted at our institution a sample size of 60 was arrived at for each group. Randomisation of the participants was done according to a computer-generated randomised number table and 
opaque, unlabelled sealed envelopes, opened before the procedure was to be performed.

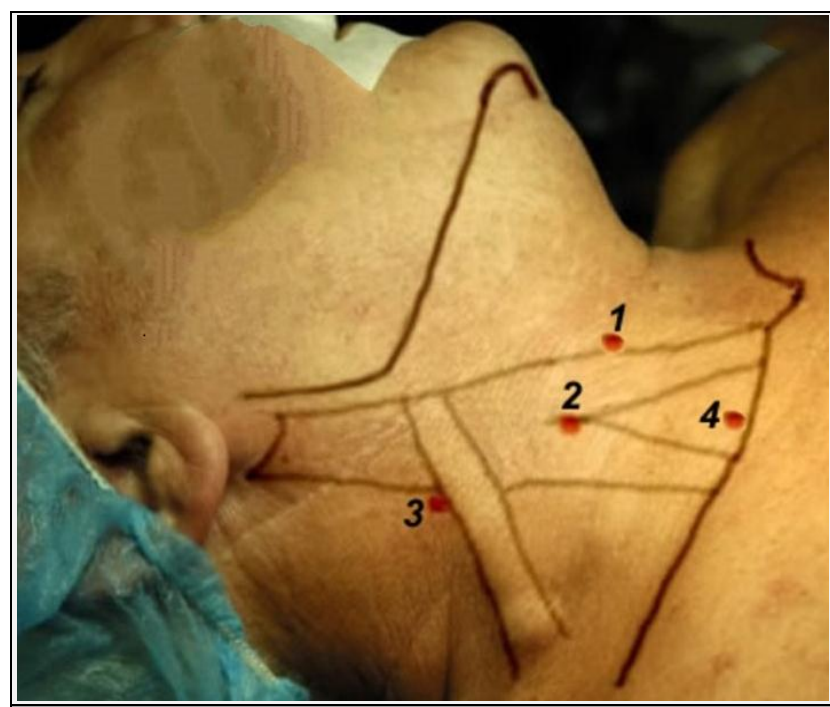

Figure 1. Patient in Supine Position with Head Turned 45 Degrees to the Left in Trendelenburg Position to Make the IJV More Prominent

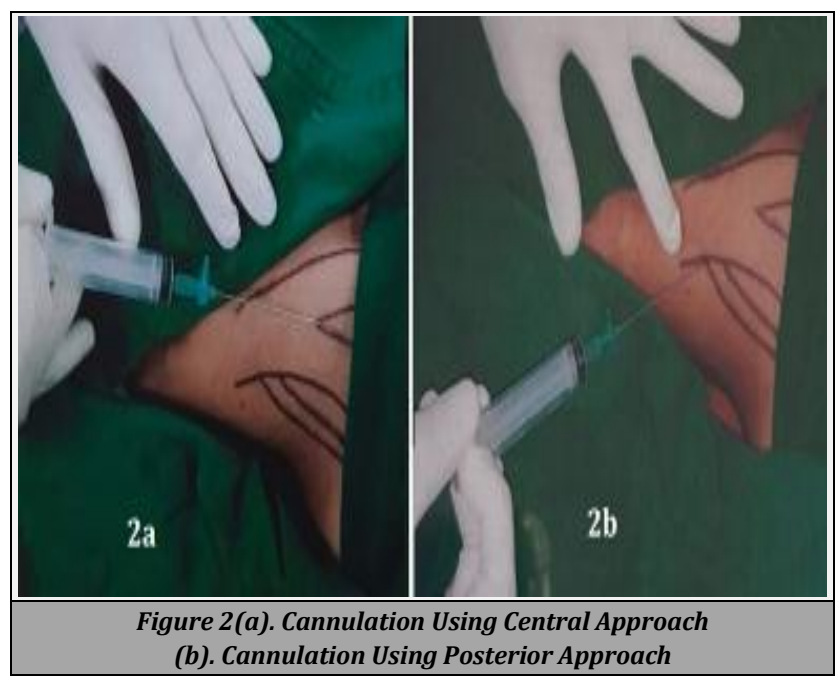

\section{Positioning}

The patient was positioned in a supine position with a $20^{\circ}$ Trendelenburg tilt. A small pillow was placed underneath the shoulders and the head turned to the left side. Under strict aseptic precautions, following landmarks were identified, the Sedillot's triangle (formed between the two heads of sternocleidomastoid muscle), external jugular vein, carotid pulsations and suprasternal notch.

\section{Catheter}

A triple lumen, 7 Fr CVC (central venous catheterisation) catheter, along with an $18 \mathrm{G} \times 7 \mathrm{~cm}$ introducer needle and 0.035 " $\times 70 \mathrm{~cm}$ 'J' tip guide wire was used for catheterisation in all cases.

\section{In Group C}

At the apex of Sedillot's triangle, $2 \%$ lignocaine was used to infiltrate the skin, then using an 18G needle under constant aspiration, the needle was introduced at the same point and advanced at an angle of $30^{\circ}$ (directing it towards the ipsilateral nipple) until there was free aspirate of dark coloured blood (Figure 1).

\section{In Group P}

The point where the external jugular vein crosses the lateral border of sternocleidomastoid was infiltrated with $2 \%$ lignocaine. Skin puncture done with an $18 \mathrm{G}$ needle made at angle of $30^{\circ}$, lifting up the bulk of the muscle, the needle was then advanced under the sternocleidomastoid directed towards the suprasternal notch until there was free aspirate of dark coloured blood (Figure 2). In both cases the right internal jugular vein was cannulated by the modified Seldinger' $s$ technique. The hub of the cannula was secured to the skin with simple sutures. All cannulations were performed by the post graduate resident under supervision.

\section{Data Recorded}

Patient demographics (age, sex, height and weight), ASA physical status, diagnosis, operative procedure, success rate of puncture of internal jugular vein on first attempt, time taken to identify the vein (needle prick to the free aspirate of dark coloured blood), time taken for cannulation (needle prick to insertion of catheter), number of carotid punctures and other complications (haematoma, pneumothorax, catheter displacement) were assessed.

\section{Statistical Methods}

Chi-square / Fisher exact test has been used to find the significance of study parameters. A p value $<0.05$ was taken as statistically significant using t-test. Results on continuous measurements are presented on Mean \pm SD (Min-Max) and results on categorical measurements are presented in number (\%). The statistical software namely SPSS 22.0 and R environment ver.3.2.2 were used for the analysis of the data.

\section{RESULTS}

Both groups were comparable in terms of demographic variables like age, gender height and weight as shown in (Table 1). Analysis of the data for the number of attempts showed that posterior approach required fewer attempts to successfully locate the vein when compared to the anterior approach. $85 \%$ of the patients were cannulated at the first attempt via the posterior approach compared to only $70 \%$ via the anterior approach (Table 2). Time required to identify the vein was significantly less with posterior approach with a mean value of $12.04 \pm 1.49$ seconds, compared to $14.27 \pm 2.30$ seconds with anterior approach, which is significant statistically. Also, the duration of cannulation was significantly lower with posterior approach with a mean value of $3.42 \mathrm{~min}$, compared to a mean value of $4.64 \mathrm{~min}$ with anterior approach as shown in (Table 3). The incidence of arterial puncture and haematoma are significantly lower with posterior approach, compared to anterior approach. We have encountered thirteen cases of arterial puncture with anterior approach, compared to only three case with posterior approach, as shown in (Table 
4). There were no instances of pneumothorax in either group. Three instances of catheter displacement (tip lying elsewhere instead of right atrium) found on post procedure X-ray was observed with the posterior approach but was not statistically significant.

\begin{tabular}{|cccc|}
\hline Parameter & Group P (n= 60) & Group C (n= 60) & P-Value \\
Age (Years) & $40.08 \pm 14.44$ & $37.30 \pm 12.17$ & $0.256(\mathrm{NS})$ \\
Gender (M / F) & $35 / 25$ & $33 / 27$ & - \\
Weight $(\mathrm{Kg})$ & $55.98 \pm 8.52$ & $54.12 \pm 6.98$ & $0.192(\mathrm{NS})$ \\
Height $(\mathrm{cm})$ & $155.70 \pm 5.44$ & $156.53 \pm 6.10$ & $0.431(\mathrm{NS})$ \\
\hline \multicolumn{4}{c}{ Table 1. Demographic Data } \\
\hline
\end{tabular}

\begin{tabular}{|ccc|}
\hline No. of Attempts & Group P (n= 60) & Group C (n = 60) \\
\hline 1 & $51(85 \%)$ & $42(70 \%)$ \\
2 & $9(15 \%)$ & $14(23.3 \%)$ \\
3 & $0(0 \%)$ & $4(6.7 \%)$ \\
\hline \multicolumn{3}{|c}{ Table 2. Number of Attempts } \\
\hline
\end{tabular}

\begin{tabular}{|lccc|}
\hline \multicolumn{1}{|c|}{ Parameter } & $\begin{array}{c}\text { Group P } \\
(\mathbf{n = 6 0 )}\end{array}$ & $\begin{array}{c}\text { Group C } \\
(\mathbf{n = 6 0})\end{array}$ & P-Value \\
\hline Time to Identify the Vein (Seconds) & $12.04 \pm 1.49$ & $14.27 \pm 2.30$ & $<0.001^{*}$ \\
\hline Duration of Cannulation (Seconds) & $205.54 \pm 29.58$ & $278.51 \pm 41.14$ & $<0.001^{*}$ \\
\hline \multicolumn{4}{|c|}{ Table 3. Results in Both Groups } \\
\hline${ }^{* \mathrm{p}<0.05 \text {, Statistically Significant }}$ \\
\hline
\end{tabular}

\begin{tabular}{|cccc|}
\hline Parameter & $\begin{array}{c}\text { Group P } \\
(\mathbf{n = 6 0 )}\end{array}$ & $\begin{array}{c}\text { Group C } \\
(\mathbf{n = 6 0 )}\end{array}$ & P-Value \\
\hline Arterial Puncture & 3 & 13 & $<0.001^{*}$ \\
Haematoma & 2 & 5 & 0.439 \\
Pneumothorax & 0 & 0 & 1.0 \\
Catheter Displacement & 3 & 0 & 0.244 \\
\hline \multicolumn{4}{c}{} \\
\hline${ }^{*} \mathrm{p}<0.05$, Statistically Significant \\
\hline
\end{tabular}

\section{DISCUSSION}

Central venous catheterization has been one of the most crucial advances in medicine. While these CVCs are commonplace, now they have evolved over several generations and today have many varied uses. In our institute, the central approach is the method that most residents learn and perform on a day to day basis. While it has success rate of $85-95 \%, 14$ it is often associated with complications such as arterial puncture. The posterior approach, on the other hand, is less often learnt and used but has been found to be as efficient and with a lower incidence of complications. ${ }^{11,12}$

In a study conducted by Shanta Chandrasekaran et al. ${ }^{15}$ they analysed the relation of IJV (internal jugular vein )to CCA (common carotid artery) and found that amongst the patients studied $74 \%$ and $80 \%$ on the right and left sides respectively had the safe (i.e. lateral / antero-lateral) relation while the remaining had the unsafe (i.e. anterior) relation. In a study conducted by Thomas Suarez et $\mathrm{al}^{16}$ found that if the patient's condition allows then the combination of Trendelenburg position + lateral approach (irrespective of head rotation), would give the maximum cross-sectional area to successfully cannulate the IJV. In this regard we considered comparing the traditional and commonly used central approach to the posterior approach in terms of success of cannulation and complications.

All patients were matched for age, weight and height. There was no significant statistical difference between the two groups. In our study, in 51 (85 \%) patients, the IJV could be identified and cannulated on the first attempt via the posterior approach, while only $42(70 \%)$ patients via the central approach group. The remaining $9(15 \%)$ patients in the posterior group, the vein was identified on the second attempt, while in the central group $14(23.3 \%)$ in the second attempt and $4(6.7 \%)$ in the third attempt vein was identified. This correlation was found to be statistically significant $(p=0.054)$. Our results concurred with studies conducted by Mohan Chandralekha $\mathrm{V}$ et $\mathrm{al}^{17}$ and T. Lamkinsi et al. ${ }^{12}$ Thus we found that the posterior approach required fewer attempts to locate the IJV and hence this in turn would reduce the risk of complications.

The mean time to locate the vein was $12.04 \pm 1.49$ seconds in posterior approach group and $14.27 \pm 2.30$ seconds in the central approach group. This was found to be strongly significant $(p<0.001)$, indicating that it took a shorter duration of time to identify the vein using the posterior approach. This result was similar to a study conducted by B Vishnu Mahesh Babu et al. ${ }^{11}$

The duration of cannulation in our study was defined as the time taken from puncture of vein to catheter insertion into the internal jugular vein. In the study conducted by Mohan Chandralekha $\mathrm{V}$ et al.18 they found that the duration of cannulation was shorter via the posterior. Similarly, in our study the Mean \pm SD duration was $205.54 \pm 29.58$ seconds in the posterior group compared to $278.51 \pm 41.14$ seconds in the central group, this was found to be strongly significant with a $p<0.001$. The posterior approach had a shorter duration of cannulation when compared to the central approach. The shorter duration for cannulation via the posterior approach (in Trendelenburg position) is probably because of the greater cross-sectional area of the IJV achieved.16,18,19,20 This would allow faster identification of the IJV and easier threading of the catheter.

The rate of carotid puncture with the central approach was $21.7 \%(13 / 60)$ \& it was much higher than the posterior approach where it was only $5 \%(3 / 60)$, this was found to be statistically significant $(\mathrm{p}<0.001)$. Our results are similar to the studies conducted by M. Mathur et al. ${ }^{21}$ On encountering carotid puncture, the needle was withdrawn and removed immediately, and firm pressure was applied for a few minutes. Central approach involves identifying landmarks, this is not always possible particularly in obese / short neck patients, also very often the IJV is located overlapping the CCA and hence the risk of going through the vein and into the artery also increases, these maybe the reasons for the higher incidence of carotid puncture via the central approach. ${ }^{14-16,20,22}$

Most of the studies report a lower incidence of haematoma with the posterior approach.11,12 There were three instances of haematoma by the posterior approach and five in the central approach. This was statistically not significant $(p=0.439)$. The haematomas in all cases resolved within $24-48$ hours. The lower incidence of haematoma formation via the posterior approach could be as a result of fewer episodes of arterial puncture by this route.

Catheter displacement leads to the tip of the catheter to end elsewhere instead of the right atrium, though still functional, this may lead to false central venous pressure readings and non-functioning ports. ${ }^{23,24}$ Three cases in the posterior group had a malpositioned or displaced catheter tip and none in the central approach, this was not statistically significant $(p=0.244)$. The reason for this maybe as a result of 
the lateral entry into the IJV in the posterior approach causing the guide wire to enter at an angle.

In our study we did not record data regarding limitation of neck movement but we postulate that since the point of entry and securing of the hub of the catheter is beyond the SCM muscle in the posterior approach when compared to the central approach where the suture is invariably on the SCM muscle, it will allow the patient to be more comfortable and allow more movement of the neck.

\section{Limitations}

The study has been conducted in a small cohort of patients, further study in patients who are obese, those post surgeries on the neck and catheterizing using haemodialysis catheters is required to improve the generalizability of the study. In this study all lines were secured by the post graduate resident under supervision who had minimal experience and an initial learning curve, hence assessment of efficacy of both approaches when performed by anaesthesiologists with experience is required to improve the strength of the study.

\section{CONCLUSIONS}

Central venous cannulation by posterior approach is better than the central approach in terms of success of cannulation and fewer associated complications. The posterior approach while a viable and efficient alternative to the central approach involves a small learning curve and some experience. It is especially useful in patients who are obese or who have a short neck in whom the landmarks are not obvious. Residents and practicing anaesthesiologists could benefit from having another approach to cannulate the internal jugular vein especially in situations where the common approaches have failed them.

Data sharing statement provided by the authors is available with the full text of this article at jemds.com.

Financial or other competing interests: None.

Disclosure forms provided by the authors are available with the full text of this article at jemds.com.

\section{REFERENCES}

[1] Beheshti MV. A concise history of central venous access. Tech Vasc Interv Radiol 2011;14(4):184-5.

[2] Peters JL. The history of central venous access. Cent Venous Catheters 2009;(1818):1-13.

[3] Gow KW, Tapper D, Hickman R0. Between the lines: the 50th anniversary of long - term central venous catheters. J Assoc Vasc Access 2017;22(4):165-77.

[4] Rupp SM, Apfelbaum JL, Blitt C, et al. Practice guidelines for central venous access: a report by the American society of anesthesiologists task force on central venous access. Anesthesiology 2012;116(3):539-73.

[5] Higgs ZCJ, Macafee DAL, Braithwaite BD, et al. The Seldinger technique: 50 years on. Lancet 2005;366(9494):1407-9.
[6] Bannon MP, Heller SF, Rivera M. Anatomic considerations for central venous cannulation. Risk Manag Healthc Policy 2011;4:27-39.

[7] Mumtaz S, Singh M. Surgical review of the anatomical variations of the internal jugular vein: an update for head and neck surgeons. Ann R Coll Surg Engl 2019;101(1):26.

[8] Ishizuka M, Nagata $H$, Takagi $K$, et al. Right internal jugular vein is recommended for central venous catheterization. J Invest Surg 2010;23(2):110-4.

[9] Soni NJ, Reyes LF, Keyt H, et al. Use of ultrasound guidance for central venous catheterization: a national survey of intensivists and hospitalists. J Crit Care 2016;36:277-83.

[10] Tempe DK, Virmani S, Agarwal J, et al. The success rate and safety of internal jugular vein cannulation using anatomical landmark technique in patients undergoing cardiothoracic surgery. Ann Card Anaesth 2013;16(1):1620.

[11] Babu BVM, Rao ASK, Srikanth B. Comparision of posterior and anterior approaches for internal jugular venous cannulation - a prospective \& randomised controlled study. International Journal of Scientific Study 2014;2(2):35-8

[12] Lamkinsi T, Kettani A, Belkhadir Z, et al. Cathétérisme veineux jugulaire interne: quelle est la meilleure voie d'abord? Annales Françaises d'Anesthésie et de Réanimation 2012;31(6):512-6.

[13] Botha R, Van Schoor AN, Boon JM, et al. Anatomical considerations of the anterior approach for central venous catheter placement. Clin Anat 2006;19(2):101-5.

[14] Srinivasan S, Govil D, Gupta S, et al. Incidence of posterior wall penetration during internal jugular vein cannulation: a comparison of two techniques using real-time ultrasound. Indian J Anaesth 2017;61(3):240-4.

[15] Chandrasekaran S, Chandrasekaran V. Anatomical variations of the internal jugular vein in relation to common carotid artery in lesser supra clavicular fossa - a colour doppler study. Int J Basic Med Sci 2011;1(5):23541.

[16] Suarez T, Baerwald JP, Kraus C. Central venous access: the effects of approach, position and head rotation on internal jugular vein cross-sectional area. Anesth Analg 2002;95(6):1519-24.

[17] Chandralekha MV, Darlong V, Kashyap L. Internal jugular vein cannulation - comparison of central approach (palpation method) and posterior approach (nonpalpation method). Eur J Anaesthesiol 2005;22:197-8.

[18] Clenaghan S, McLaughlin RE, Martyn C, et al. Relationship between Trendelenburg tilt and internal jugular vein diameter. Emerg Med J 2005;22(12):867-8.

[19] Parry G. Trendelenburg position, head elevation and a midline position optimize right internal jugular vein diameter. Can J Anesth 2004;51(4):379-81.

[20] Dhulkhed V, Reddy A, Gupta A, et al. An observational study of change in diameter of right internal jugular vein with various body positions in volunteers with the aid of 2-dimensional ultrasonography. Internet $\mathrm{J}$ Anesthesiol 2012;21(2):1-6.

[21] Mathur M, D'Souza AVL, Prasad D, et al. A comparative study of central versus posterior approach for internal jugular hemodialysis catheter insertion. Indian J Nephrol 2015;25(5):265-8. 
[22] Miki I, Murata S, Nakazawa K, et al. Anatomical relationship between the common carotid artery and the internal jugular vein during head rotation. Ultrasound 2014;22(2):99-103.

[23] Tyagi A, Kumar S, Sethi AK, et al. Mechanical and infectious complications of central venous catheterizations in a tertiary-level intensive care unit in northern India. Indian J Anaesth 2012;56(4):342-7.

[24] Pikwer A, Baath L, Davidson B, et al. The incidence and risk of central venous catheter malpositioning: a prospective cohort study in 1619 patients. Anaesth Intensive Care 2008;36(1):30-7. 